\title{
DOES ESCALATION OCCUR IN CYCLES? EVIDENCE FROM THE NEOGENE.
}

HANSEN*, Thor A., Dept. of Geology, Western Washington University, Bellingham, WA 98225, U.S.A.; GRAHAM, Scott, E., Dept. of Geology, Western Washington University, Bellingham, WA 98225, U.S.A.; KELLEY, Patricia H., Dept. of Geology and Geological Engineering, Univ. of North Dakota, Grand Forks, ND 58202, U.S.A.

A survey of naticid gastropod drilling rates from samples of Cretaceous through Oligocene age (over 46,000 specimens) found a cyclical pattern in drilling rates linked to mass extinctions. This led us to formulate a model of escalation cycles wherein an overall pattern of escalation of prey is interrupted by mass extinctions. In this model, mass extinctions selectively kill escalated prey, allowing greater success of predators and causing an increase in drilling rates during postextinction recoveries. Drilling rates subsequently decline as the prey escalate their defenses. The cycle begins again with the next extinction. One complete cycle can be seen in the Paleogene, initiated by the Cretaceous-Tertiary extinction, and a second one appears to begin with the Eocene-Oligocene extinction.

Do these cycles persist into the Neogene? Two mass extinctions have been reported for the Neogene, in the middle Miocene and at the Plio-Pleistocene boundary. Our model of escalation cycles predicts that drilling rates in the Oligocene and early Miocene (following the cycle initiated by the Eocene-Oligocene extinction) should have declined until the mid-Miocene extinction. At this point, drilling rates should have risen abruptly, and then declined gradually until the Plio-Pleistocene boundary. The Plio-Pleistocene extinction should have initiated a new cycle producing another abrupt rise in drilling rates.

To test the applicability of this model in the Neogene, we analyzed samples from 13 stratigraphic horizons from Maryland, Virginia and North Carolina, ranging in age from early Miocene to Pleistocene (over 38,000 specimens). Stratigraphic coverage is relatively complete except for gaps in the upper Oligocene and in the lower Miocene. Our results partially confirm the predictions made by the model of escalation cycles. Drilling rates were very low in the earliest Miocene and then rose abruptly in the mid-Miocene, followed by a long gradual decline. However, this decline in drilling rates continues into the Pleistocene without the rise that was predicted to follow the Plio-Pleistocene extinction. 